\title{
Reform of the British health services: How will it affect services for people with rheumatic diseases?
}

The British government's proposals for reform of the National Health Service (NHS) have aroused widespread interest and comment in the medical press and in the media both at home and overseas. ${ }^{1}$ Few working within the service or users of it would doubt the real need for a review. It is after all 40 years from its inception and one has only to look at the length of the waiting lists, the state of our hospitals, or the morale of our health workers (the result of serial NHS reorganisations and a perennial failure of resources to keep pace with demand) to appreciate that the service is limping rather than moving forward at the present time.

The package of proposals contained in the government white paper entitled 'Working for patients', ${ }^{2}$ published in March, if followed through, presages the most radical and fundamental changes to the organisation of the service since it was introduced in 1948. It is true that the twin principles that treatment should be free at the point of consumption and that the service should be primarily tax financed remain. It is the financial arrangements for the delivery of care and, in particular, the introduction of the 'internal market' (aimed at improving efficiency through competition ${ }^{3}$ ) that have proved to be so controversial. In essence, the scheme separates the 'purchasers' of services -that is, the district health authorities or budgetholding general practitioners (GPs)-from the 'providers' of services-that is, the hospitals, which either become autonomous 'self-governing hospital trusts' accountable only to the Secretary of State, or remain under district health authority control. It is intended that the purchasing authority will contract for the provision of a service on the most favourable terms available, even if that involves a hospital some distance away. Certain services, termed 'core services' (yet to be clearly defined), will, however, be provided from within every district. In determining its prices a hospital (whether self governing or not) will be required to take into account a hitherto unknown financial burden-namely, the interest payable on its own land and buildings. Self-governing hospitals will, however, have considerable flexibility in such matters as terms and conditions of service and the use to which cash surpluses might be put.

The white paper has been strongly criticised by such medical bodies as the British Medical Association, the Royal College of Physicians, ${ }^{4}$ and the Royal College of General Practitioners, by voluntary organisations, by the pharmaceutical industry ${ }^{5}$, by medical economists, ${ }^{6}$ and by politicians of all parties. Indeed, there is growing evidence that the public reaction to its publication might have dented government support in recent elections. Much of the criticism derives from the lack of precise information on how the schemes will operate, from the complete absence of preliminary pilot experiments, from the conspicuous lack of extra funding, and from the concern over the ability to cope with the enormous increase in demand for information technology and accounting expertise that would be generated. Doubts have also been expressed as to whether self-governing hospitals would be able to stay in business, whether medical and paramedical education in finance driven hospitals might not be put in jeopardy, and, lastly (and most importantly), whether patient care might not suffer and patient choice be diminished. Some aspects were generally welcomed. These include the promotion of resource management and of medical audit, the tightening up of consultants' contracts, and the general principle that money might follow patients (across district boundaries). The fact that all of these 'good' features could have been achieved without recourse to the internal market did not pass unnoticed by the critics.

How is all this going to affect services for patients with rheumatic diseases? Concern has already been expressed on this score by the president of the British Society for Rheumatology. ${ }^{7}$ The British League Against Rheumatism (BLAR) set up a working party (composed of J Dickson, J Gaffin, R Grahame (chair), I Haslock, R N Maini (BLAR president-ex officio), J Maycock, and $\mathrm{P} H \mathrm{H}$ Wood) to draw up a response to the white paper on its behalf, which was duly forwarded to the Secretary of State on 25 May 1989. (BLAR is the umbrella organisation that unites the many professional and 
lay bodies concerned with providing care for people with rheumatic diseases. Through its constituent organisations it also represents many millions of patients themselves. BLAR is also the United Kingdom link to EULAR and ILAR.) Concerns were expressed and some 12 questions posed about the possible impact of the white paper proposals on the care of people with rheumatic diseases. These are quoted verbatim.

" 1 Limiting GP budgets. As we understand it (section 4, working paper 4 , 'Working for patients') this could be a serious threat to the doctor-patient relationship. Patients with chronic disabling diseases are expensive to treat in terms both of time and treatment costs. There is a real fear that economic considerations would take precedence over clinical need, and that trust (that essential feature of medical care) would be eroded. How would 'financial weighting' for patients with chronic arthritic conditions be set so as to ensure that patients with arthritis do not experience difficulty in being accepted onto a GP's list because 'they were so expensive to treat'?

Patients with diseases such as early rheumatoid arthritis (RA) and systemic lupus erythematosus (lupus) in need of early expert specialist advice and beneficial drug treatment capable of stemming the damaging effects of the disease may be denied them on grounds of financial stringency. Prescribing non-steroidal anti-inflammatory drugs (NSAIDs), requesting diagnostic investigations and referral to a hospital outpatient rheumatology clinic, where appropriate, are all essential components of good care, but may be withheld 'when the budget is running out'. What guarantee can patients with rheumatic diseases have that they will not be deflected from specialist help by despairing GPs with statements like 'It's only rheumatism. You'll have to learn to live with it', only to suffer the inevitable disastrous (and more expensive) consequences of the late effects of untreated disease. Will the process of audit be extended to cases of inappropriate non-referral for specialist rheumatological care?

2 Rheumatology services should be specifically designated as core services (as defined in the white paper) in every health district because of their fundamental impact on health care. Only in this way can an integrated service be preserved for this group of patients whose diseases combine high prevalence with chronicity, with physical immobility, and with heavy demands on community health services-for example, home nursing. Will there be central direction to health authorities to ensure that rheumatology is designated a core service in all districts?

3 What is to be done to preserve the delicate multidisciplinary teamwork relationship that exists between rheumatologists, paramedicals, and orthopaedic surgeons dedicated to arthritis surgery? Will the Secretary of State ensure that the process of audit of a multidisciplinary specialty like rheumatology be itself multidisciplinary?

4 An important aspect of patient care in diseases like RA is shared care between hospital rheumatologist and the patient's GP, especially in the monitoring of treatment with certain so called 'second line' agents. These drugs? require regular blood tests in order to ensure safety. Who $\vec{\Rightarrow}$ becomes responsible for the payment for the essential blood tests-the GP or the hospital clinic? Will serious? (even life threatening) side effects go undetected if this matter is not clarified? How will the Secretary of State $\frac{\bar{p}}{\partial}$ ensure that contractual arrangements regarding rheumato- $\stackrel{\mathbb{Q}}{Q}$ logy services are costed with patient safety, rather than cheapness, as the prime consideration?

$\overrightarrow{0}$

5 How will multidisciplinary facilities such as pain clinics, respite care, and rehabilitation be financed and managed $\vec{\omega}$ under the new arrangements proposed for the NHS?

6 Who will be responsible in the reorganised NHS for health education and health promotion, which is important to patients with chronic diseases, who need to comply with drug therapy, lose weight, and understand the link $\overrightarrow{.}$ between nutrition, the environment, and their disease?

7 When care is shared, how will financial responsibility for drugs prescibed be allocated between GP and hospital pharmacy. Is there not a danger of increased purchase of $\vec{z}$ 'over the counter' medicine and thus a reduction of $O$ monitoring for side effects?

8 Will the review help to resolve the problem caused to patients by the shortage of occupational therapists and $\mathbb{D}$ physiotherapists? How will the responsibility for traini $\hat{R}_{0} \overrightarrow{0}$ allied health professionals be allocated? We would empla sise that adequate training facilities are a sine qua non $8 \mathrm{~g}$ an effective service, and this applies not only to doctors buㅏ응 also to nurses and therapists.

9 How will the provision of equipment and home adapta-o tions needed by people with arthritis be facilitated within the NHS? Hospital occupational therapists may assess the $\mathbb{Q}$ patient's needs, but the provision of equipment is split. If $\overrightarrow{\vec{O}}$ the need for equipment relates to a nursing need the health authority in which the patient lives provides it; if it is medical treatment the discharging health authority provides it; and if the equipment is needed in the patient's home the local social service department becomes responsible. Will the current separation of occupational: therapy assessment from the budget for aids and equip- 3 ment be changed in the new structure?

10 What is the Secretary of State's intention with regard to releasing funding for setting up of a reliable information gathering system appropriate to rheumatology, where the 9 bulk of the work is outpatient based? Such a system should $D$ analyse not only the patient numbers but also a weighting for complexity and time taken.

11 Will the reciprocal arrangements that exist between medical schools and their hospital management boards be 0 disturbed when a teaching hospital opts for self govern- $-\omega$ ment? If so, will this not both damage patient care on the one hand and undergraduate medical care on the other? 12 Would the Secretary of State consider the idea of having consumer representation from this largest group of pa-? tients on management boards of self-governing hospitals in order to help to ensure that patients' needs are adequately recognised?" 
An early meeting with the Secretary of State was requested. At the time of writing (September 1989) no response has as yet been forthcoming.

Rheumatology Unit,

R GRAHAME

Guy's Hospital,

London SE1 9RT

\section{References}

1 Whitney C. Thatcher's plan for changes in health services: outcry rises from all sides. New York Times 1989 June 26: A10-11.
2 Secretaries of State for Health, Wales, Northern Ireland, and Scotland. Working for patients. London: HMSO, 1989. (Cmnd 555.)

3 Enthoven A C. Reflexions on the management of the National Health Service. London: The Nuffield Hospitals Provincial Trust, 1985.

4 The Royal College of Physicians. Response to the white paper 'Working for patients'. London: Royal College of Physicians, 1989.

5 APBI. Working for patients. APBI response to the health service white paper. The Association of the British Pharmaceutical Industry, 1989.

6 Day P, Klein R. NHS review: the broad picture. Waiting for the small print. $\mathrm{Br}$ Med $J$ 1989; 298: 339-40.

7 Haslock I. Working for patients? Br J Rheumatol 1989; 28: 185-6.

\section{Notes and news}

\section{Calendar of events}

In 1989

26 Nov-2 Dec International seminar on the treatment of rheumatic diseases. Israel

Contact Dr I Machtey, Rheumatology Service, Hasharon Hospital, PO Box 121, Petah-Tiqva 49101, Israel

26-30 Nov 2nd International conference on systemic lupus erythematosus. Singapore Contact Ms Nina Sharma, Communication Consultants, 20 Kramat Lane, 03-07 United House, Singapore 0922. Tel (65) 7333304

3-6 Dec 2nd ASEAN congress of rheumatology. Manila, Philippines

Contact Secretariat, 2nd ASEAN Congress of Rheumatology, Room 312, NEWC Building, Cor. Escado and San Marcelino, Ermita 1000, Manila, Philippines. Tel 507391

In 1990

10 Jan

8-9 Feb Spinal disorders Contact Mrs W Mathews, Rheumatology, Department, St Thomas's Hospital, London SE1 7EH

$14 \mathrm{Feb}$

RSM: Combined meeting of the open and rheumatology and rehabilitation section Contact Dr D R Swinson, Wrightington Hospital, Wigan, Lancs WN6 9EP

9 Mar

RSM: Presidential address (Dr J Moll)

Contact Dr D R Swinson, Wrightington Hospital, Wigan, Lancs WN6 9EP
11-16 Mar Xth Pan American league against rheumatism congress

Contact Secretariat, Apartado Postal 71-275 06900 Mexico, DF Mexico. (We have a limited stock (c. 20) of application forms in the BSR office: Tel 012243739 , if interested.)

22-23 Mar Rheumatology 1990 -Centre for rheumatic diseases 25th anniversary symposium. Royal College of Physicians and Surgeons of Glasgow

Contact Mrs L Leckenby, University Department of Medicine, Glasgow Royal Infirmary. Tel 0415523535 (Ext 5423)

6-7 Apr Association of Physicians of Great Britain and Ireland

Contact Professor S Thomlinson. The Manchester Diabetes Centre, 130 Hathersage Rd, Manchester

16-19 May VIth EULAR symposium. Athens, Greece. 'Systemic manifestations of the rheumatic diseases'

Contact Eular ' 90 Symposium Secretariat, 10 Loukianou Street, GR-106 75 Athens, Greece. Tel 017218 276, 7228784. Fax 017218276

18 May BSR basic rheumatology course Contact Dr Peter Dawes, Staffordshire Rheumatology Centre, Haywood Hospital, High Lane, Burslem, Stoke-On-Trent

13-16 Jun XXIII Scandinavian congress of rheumatology, Tampere, Finland

Contact Congress Team, PO Box 227, SF00131, Helsinki, Finland. Tel Int'l code+ 3580176866

29-30 Jun RSM: Provincial meeting in York Contact Dr D R Swinson, Wrightington Hospital, Wigan, Lancs WN6 9EP 